\title{
FIM DAS COLIGAÇÕES PROPORCIONAIS E SEUS EFEITOS NO LEGISLATIVO MUNICIPAL BRASILEIRO: UMA ANÁLISE A PARTIR DO RESULTADO ELEITORAL DE 2020
}

\author{
The Effects of the End of Party Coalition in Party-List Proportional Representation \\ in Brazilian Local Legislative Elections: an analysis based on the 2020 elections
}

(iD) Bruno de Almeida Passadore (D) Camila Rodrigues Forigo

Resumo: No presente estudo, será analisado o impacto da proibição das coligações partidárias nas disputas proporcionais a partir do resultado das eleições municipais brasileiras de 2020. Tal proibição insere-se entre diversas reformas institucionais cujo objetivo declarado é garantir maior ideologização e redução do número de legendas partidárias, e, com isso, promover maior aproximação e confiança entre parlamentar e eleitor, bem como maior estabilidade governamental. Como método de pesquisa, serão analisados dados previamente tabulados por canais de comunicação acerca dos resultados das eleições de 2020 e, a partir de revisão bibliográfica, serão apresentadas considerações finais nas quais se objetiva concluir que o fim das coligações em eleições proporcionais não apresentou efeitos positivos ao sistema representativo brasileiro, ao menos em nível municipal.

Palavras-chave: Coligações proporcionais. Eleições municipais brasileiras de 2020. Partidos políticos. Dispersão partidária. Emenda Constitucional no 97.

\begin{abstract}
This study analyzes the prohibition of party coalitions in party-list proportional representation disputes and its consequences for the 2020 Brazilian local elections. This prohibition may be inserted in a range of institutional reforms that aim to reduce the number of political parties in Brazil, promote greater rapprochement and trust between Congress members and voters, and greater government stability. The research used data from the 2020 local elections treated and disseminated by the Brazilian mass media. Based on a bibliographic review, we concluded that the prohibition of party coalitions in party-list proportional representation did not have positive effects on the Brazilian representative system, at least at the local level.

Keywords: Party coalitions in party-list proportional representation. 2020 Brazilian local elections. Political parties. Party dispersion. Constitutional amendment 97.
\end{abstract}

Artigo recebido em 9 fev. 2021 e aprovado em 6 maio 2021

Editor responsável: Luiz Magno Pinto Bastos Junior

DOI: https://doi.org/10.53323/resenhaeleitoral.v25i1.129 


\section{Introdução}

No presente estudo, procura-se analisar parte dos impactos da Emenda Constitucional no 97 de 2017 nas eleições municipais de $2020^{1}$. Especificamente, será tratado o tema da proibição das coligações partidárias nas disputas eleitorais proporcionais.

A reforma eleitoral em alusão decorreu de certa ânsia popular por mais respostas institucionais em virtude de uma crise de representatividade presente no sistema democrático brasileiro. Especificamente, aponta-se o descrédito da denominada "política tradicional" em fazer frente aos anseios sociais decorrentes de um constitucionalismo evidentemente descumprido. A título exemplificativo, tem-se recente pesquisa do Instituto Datafolha datada de agosto de 2020 apontando que apenas 17\% dos brasileiros estão satisfeitos com o funcionamento do Congresso Nacional (GIELOW, 2020).

Nesse cenário, a busca por reformas institucionais que possam restaurar, ao menos em parte, a confiança social na democracia representativa se mostra como algo de primeira urgência. E esse é exatamente um dos objetivos declarados da reforma em estudo. Assim, por meio de mecanismos que garantiriam maior ideologização e redução do número de legendas partidárias, haveria maior aproximação e confiança entre parlamentar e eleitor e, com isso, seriam trazidos benefícios ao sistema democrático como um todo.

Por sua vez, avaliando os resultados eleitorais de 2020, levantam-se dúvidas sobre o efetivo cumprimento, pela reforma, do objetivo declarado com o fim das coligações proporcionais. Ainda, será apresentada reflexão sobre eventuais efeitos contrários aparentemente não pensados pela reforma em estudo.

Como método de pesquisa, serão analisados dados previamente tabulados por canais de comunicação acerca dos resultados das eleições de 2020 e, a partir de revisão bibliográfica, serão apresentadas considerações finais nas quais se desafiará a ideia de que o fim das coligações em eleições

\footnotetext{
${ }^{1}$ Aponta-se que apesar de a proibição de coligações em eleições proporcionais ser datada de reforma constitucional de 2017, ela não se aplicou às eleições de 2018 por disposição expressa do art. 2º da Emenda Constitucional no 97. Confira-se: "Art. 2ํㅗ A vedação à celebração de coligações nas eleições proporcionais, prevista no $\int 1^{\circ}$ do art. 17 da Constituição Federal, aplicar-se-á a partir das eleições de 2020”. Portanto, as primeiras eleições em que proscritas as coligações proporcionais se deram justamente em 2020.
} 
proporcionais trouxe efeitos positivos ao sistema eleitoral brasileiro, ao menos em relação aos poderes legislativos e executivos de nível municipal.

Registra-se, por fim, que ante à pouca literatura técnica produzida sobre o tema até o momento - em razão da proximidade temporal do evento estudado -, mostrou-se necessário utilizar-se em boa medida de material produzido por canais de jornalismo.

\section{A crise da democracia brasileira}

O projeto de 30 anos atrás de "construir uma sociedade livre, justa e solidária"; "garantir o desenvolvimento nacional"; "erradicar a pobreza e a marginalização e reduzir as desigualdades sociais e regionais" e "promover o bem de todos, sem preconceitos de origem, raça, sexo, cor, idade e quaisquer outras formas de discriminação" - conforme o art. 3ำ da Constituição Federal -, parece algo vazio diante da persistente pobreza, desigualdade e injustiças que se mantêm no Brasil. Tal cenário, associado a uma visão de que os quadros partidários tradicionais pouco teriam a contribuir com a melhora da qualidade de vida das pessoas, criou um ambiente absolutamente propício ao desencanto em relação às instituições democráticas brasileiras que acabaram sendo colocadas em claro descrédito social.

O risco, por sua vez, é que a população, claramente insatisfeita com a situação, em detrimento de buscar novas formas de aprofundamento democrático para fazer valer a sua plena dignidade e de seus pares, passe a desconfiar do regime iniciado em 1988. Como lembra Castells (2018, p. 12), "a força e a estabilidade das instituições dependem de sua vigência na mente das pessoas", logo "se for rompido o vínculo subjetivo entre o que os cidadãos pensam e querem e as ações daqueles a quem elegemos e pagamos, produz-se o que denominamos crise de legitimidade política"2.

Portanto, a busca por formas de resgatar a confiança social e a responsividade das instituições democráticas é algo que se mostra urgente. Afinal, a história mostra que o esgotamento da crença social no sistema democrático é a antessala do autoritarismo (MAZOWER, 2001, p. 38) ${ }^{3}$.

${ }^{2} \mathrm{Na}$ mesma linha, Dahl (2001, p. 63) aponta que "a existência de convicção bastante disseminada entre cidadãos e líderes, incluindo as convicções nas oportunidades e nos direitos necessários para a democracia", é algo que aumenta substancialmente as chances de sucesso de um regime democrático.

${ }^{3}$ Afinal, quando o regime democrático falha com a nação, passa-se a admitir que aquele seja sacrificado para a continuação desta ou, como apontou Hitler, "quando uma consti- 
Em outras palavras, em momentos de crise de legitimidade democrática, a resposta deve ser resgatar a lealdade das massas aos marcos constitucionais que a duras penas foram conquistados, sob pena de cairmos em demagogias arriscadas (LEBRUN, 1984, p. 66-67) ${ }^{4}$.

\section{O papel dos partidos políticos e sua falta de representatividade}

A falta de identidade entre representantes e representados é um dos temas mais significativos na crise institucional democrática brasileira. Como apontou-se anteriormente, menos de $20 \%$ da população efetivamente se mostra satisfeita com o funcionamento congressual. É marcante, portanto, a distância entre representantes e representados.

Se não há uma resposta simples para essa questão, podem ser percebidos problemas que evidenciam a crise de representatividade. Entre eles destaca-se a existência de 33 partidos aptos à disputa política no Brasil, segundo dados do Tribunal Superior Eleitoral de 2020 (TRIBUNAL SUPERIOR ELEITORAL, 2020), algo que inviabiliza qualquer tipo de vinculação ideológica entre eleitorado e parlamentares. Ademais, essa grande permissividade na criação e manutenção de partidos pode ser vista como uma fábrica de organizações fundadas no clientelismo e troca de favores muitas vezes pouco republicanos que também dificultam a estabilidade de governos.

Como bem aponta Tavares (apud NORONHA et al., 2016, p. 46), o sistema multipartidário pode acentuar a existência de "legendas de aluguel", que tanto desorganizam as relações políticas. Há, assim, a necessidade de serem criadas barreiras contra a "perpetuação de partidos sem real vocação para defesa de uma ideologia, de um segmento social, ou mesmo sem real interesse de se firmar como alternativa útil de representação política".

tuição se revela inútil, a nação não morre. A Constituição é alterada" (apud MAZOWER, 2001, p. 38). Também neste sentido, Dahl (2001, p. 173) afirma: "Durante uma crise severa e prolongada, aumentam as chances de que a democracia seja derrubada por líderes autoritários, que prometem encerrar os problemas com métodos ditatoriais rigorosos. É claro, esses métodos exigem que as instituições e os procedimentos essenciais da democracia sejam postos de lado".

${ }^{4}$ Em sentido próximo, Mazower (2001, p. 35) aponta que os nazistas exploraram sobremodo a incapacidade dos sistemas democráticos do entreguerras em fazer frente à pauperização social do período: 'Eles [os nazistas] criticavam a democracia por ser 'burguesa': indolente, materialista e incapaz de despertar a simpatia das massas, refletindo as aspirações de uma geração mais velha, cujos políticos usavam fraque e cartola”. 
Nessa linha, a referida Emenda Constitucional no 97 de 2017 foi pensada com o objetivo de reduzir a fragmentação partidária e, com isso, formar agremiações mais próximas do cidadão e capazes de formar governos mais estáveis. Tal objetivo pode ser extraído do relatório da Comissão de Constituição e Justiça e de Cidadania (CÂMARA DOS DEPUTADOS, 2017) em relação à Proposta de Emenda Constitucional no 282/2016, a qual deu origem à emenda constitucional aqui estudada:

[A] pulverização de partidos políticos no Congresso Nacional, sem que novas medidas de fortalecimento da identidade e fidelidade partidárias tenham sido eficazmente implementadas, criam dificuldades para o funcionamento do Poder Legislativo e contribui para um maior distanciamento entre a população e seus representantes. [...] Assim, em um modelo de democracia partidária tal como o desenhado pela Constituição de 1988, as coligações em eleições proporcionais se revelam corpos estranhos ao sistema, de sorte que a medida ora proposta na PEC no 282/2016, além de não enfrentar qualquer obstáculo à sua admissibilidade, revela-se salutar para a democracia brasileira. Com essa medida, é de se esperar o fortalecimento das agremiações, a redução da fragmentação e das distorções do sistema representativo.

Mas, afinal, por qual a razão as coligações gerariam tamanha distorção no sistema político representativo?

\section{Os problemas trazidos pelas coligações em eleições proporcionais}

As coligações partidárias em eleições proporcionais sempre foram tidas como um campo fértil para uniões partidárias ocasionais, centradas exclusivamente no momento do sufrágio. Por serem carentes de significativa afinidade ideológica, muitas vezes se mostram incongruentes nos diversos entes federativos e, ainda, são tidas como fraudadoras do desejo do eleitor, já que o voto depositado em favor de determinado partido acabava por beneficiar outro em razão de eventual coligação entre eles.

Eis a lógica das coligações. Trata-se de uma aliança entre partidos precisamente com objetivo de alcançar maior número de postos nas eleições proporcionais e cuja cooperação muitas vezes é extinta tão logo os 
votos são contados e os assentos parlamentares ${ }^{5}$ divididos, sendo, portanto, bastante evidente seu caráter finalístico. Em outras palavras, forças partidárias diversas unem-se estrategicamente no intuito de maximizar potenciais ganhos e concretizar objetivos eleitorais que não poderiam ser atingidos se agissem isoladamente ${ }^{6}$.

Com as coligações, entre outras coisas, aumenta-se o tempo de propaganda e torna-se possível aos partidos menores burlar o quociente eleitoral. Afinal, conforme aponta Nicolau (2012, p. 59), o coeficiente eleitoral acaba por funcionar como uma cláusula de barreira na prática. Assim, ao se dividir o total de votos pelo número de cadeiras em disputa, chega-se a um valor numérico que, caso não superado, o partido ficará de fora da divisão de vagas, independentemente do número individual de votos que seus candidatos venham a receber.

A título de exemplo, veja-se o caso das recentes eleições municipais de 2020 na cidade de Santa Maria, Rio Grande do Sul, em que a pessoa mais votada para a câmara de vereadores da localidade acabou não se elegendo, uma vez que o partido pelo qual se candidatou - no caso, o PSOL - não atingiu o coeficiente eleitoral e, mesmo tendo o maior número de sufrágios entre os candidatos a vereador da localidade, não obteve o assento parlamentar (CURCINO, 2020). Registra-se que não se tratou de fenômeno isolado e se repetiu em outros municípios, como em Toledo, Paraná (G1 PR, 2020). É provável, por sua vez, que, caso houvesse a possibilidade de coligações partidárias, tais candidaturas viriam a ser eleitas, ao custo do aumento da dispersão partidária.

Isso ocorre porque a divisão das cadeiras legislativas, quando permitida as coligações proporcionais, era calculada de acordo com a vota-

\footnotetext{
${ }^{5}$ Exceto no Senado, já que aqui a lógica é a eleição majoritária.

${ }^{6}$ Novamente de acordo com o parecer da CCJ à PEC no 282/2016: “[A]s coligações nas [eleições] proporcionais constituem mera estratégia partidária para maximizar as chances de sucesso eleitoral. Além de sua natureza efêmera, de cunho puramente eleitoral, não há qualquer compromisso de atuação conjunta dos integrantes da coligação no curso das legislaturas para as quais foram eleitas" (CÂMARA DOS DEPUTADOS, 2017). Nesse mesmo sentido, posicionam-se Sanson e Torres (apud CAGGIANO, 2017, p. 44): “A transitoriedade convencional das uniões partidárias, por meio das coligações no período que antecede a votação nas urnas sem que haja afinidade político-ideológica ou programática, sobretudo nas eleições proporcionais, com a finalidade precípua de conquistar vantagens no pleito como a superação do quociente eleitoral - umbral e controle quantitativo -, revela uma grave deturpação na realidade brasileira”.
} 
ção das legendas coligadas somadas. Assim, em uma disputa hipotética das nove cadeiras da câmara de vereadores de uma cidade de nove mil eleitores, o coeficiente eleitoral seria de mil votos e com ele seria formado o coeficiente partidário. Logo, se os partidos A, B e C, coligados, obtivessem dois mil votos, fariam jus a dois assentos, ainda que nenhum deles isoladamente tivessem obtido mil sufrágios. Com isso, os dois candidatos mais bem votados da coligação restariam eleitos independentemente se do partido A, B ou C. Neste aspecto, a votação a um desses partidos poderia significar indiretamente a eleição de candidato de outro ainda que entre as legendas não houvesse outra relação, exceto a de estarem ocasionalmente coligados (NICOLAU, 2012, p. 61).

Ainda, apontava-se que as coligações influenciavam a formação de uniões em torno dos denominados "puxadores de votos", isto é, certos candidatos - usualmente pessoas célebres da mídia - que se mostravam capazes de levar consigo uma série de outros candidatos de diversos partidos que dificilmente obteriam votação suficiente por si próprios e permitindo-se com isso toda sorte de negociações no interior da coligação. A respeito, é usualmente citado o fenômeno Tiririca nas eleições para a Câmara dos Deputados de 2010 no Estado de São Paulo, candidato pelo então Partido da República (PR) - rebatizado de Partido Liberal (PL), nome que mantém desde $2019^{7}$.

Graças ao alto volume de votos, Tiririca permitiu que diversos candidatos da sua coligação (formada por PR, PSB, PT, PCdoB e PTdoB) fossem eleitos mesmo que menos votados que outros candidatos de coligação diversa. A votação de Tiririca, para muito além do coeficiente eleitoral, aumentou o poder eleitoral da coligação e permitiu garantir vaga na Câmara dos Deputados de políticos até então pouco representativos, como Vaderlei Siraque, do PT, e o Delegado Protógenes, do PCdoB - ambos eleitos mesmo tendo obtido menos de 30\% do coeficiente eleitoral paulista em 2010 - e alijando a vaga de outros contendedores com muito mais apoio eleitoral (SANSON; TORRES apud CAGGIANO, 2017, p. 53). Logo, o eleitor que apoiou Tiririca, teve seu voto utilizado por candidatos e partidos alheios à sua vontade e, ainda, foi desconsiderado o apoio popular de outros candidatos mais representativos que Vaderlei Siraque e Delegado Protógenes.

\footnotetext{
7 Trata-se de partido do denominado "centrão", de baixo perfil ideológico e usualmente integrante da bancada situacionista, independentemente do perfil partidário do governo.
} 
Os partidos políticos, idealmente, são vistos em seu papel conectivo entre o cidadão e o Estado, no intuito de representar aquele nas diversas instâncias de poder deste. Mostra-se compreensível, nessa linha de raciocínio, que eventual atendimento insatisfatório das expectativas populares os coloque no centro das críticas, momento em que são vistos tão somente como organizações voltadas exclusivamente à aquisição de poder político e deslocados dos anseios dos eleitores. Assim, as coligações proporcionais contribuiriam para os partidos serem vistos como cameleões ideológicos e abertos a qualquer negociata para a conquista de poder, o que, por sua vez, levaria à perda de prestígio e apoio da opinião pública (SANSON; TORRES apud CAGGIANO, 2017, p. 39-40).

Não por outra razão, a visão weberiana extremamente pessimista acerca dos objetivos dos partidos políticos se mostra bastante atual. Para Weber (apud BOTELHO, 2013, p. 476-477), ao analisar o sistema de disputa eleitoral estadunidense, "se encontram frente a frente partidos absolutamente sem convicções, meras organizações de caçadores de cargos, que elaboram para cada disputa eleitoral programas cambiantes segundo suas chances de conquistar votos" criadores de "corrupção e desperdício sem precedentes que somente um país com ilimitadas oportunidades econômicas foi capaz de suportar". Essa avaliação, como se percebe, é perfeitamente aplicável à visão do eleitorado brasileiro acerca dos partidos nacionais.

O debate sobre o fim das coligações proporcionais surgiu exatamente para combater esse cenário, mas, segundo a opinião dos autores a partir dos dados extraídos das eleições de 2020, tal objetivo não parece ter sido atingido.

\section{O resultado eleitoral de 2020, após o fim das coligações proporcionais}

O fim das coligações proporcionais, como se poderia imaginar, significou em média uma redução da fragmentação partidária. Porém, esta informação merece ser vista em seus detalhes.

De acordo com comparativos do canal G1 (VASCONCELLOS, 2020), as câmaras municipais com até seis partidos, que nas eleições de 2016 representavam 50\% dos municípios, hoje saltaram para $82 \%$. Consequentemente, a quantidade de municípios com mais de seis legendas reduziu-se substancialmente. Se em 2016 representavam 50\% do total, hoje são 18\%. 
Todavia, esse fenômeno atingiu essencialmente munícipios com não mais que 150 mil habitantes. Por outro lado, nos municípios médios - aqueles entre 150 e 500 mil habitantes - e nos denominados grandes - com mais de 500 mil -, a dispersão partidária permaneceu praticamente estável. Confira-se:

Figura 1 - Média do número de partidos nas câmaras municipais por faixa populacional

\section{Média do número de partidos nas câmaras municipais por faixa populacional}

\section{Queda ocorreu principalmente nos municípios pequenos e médios}

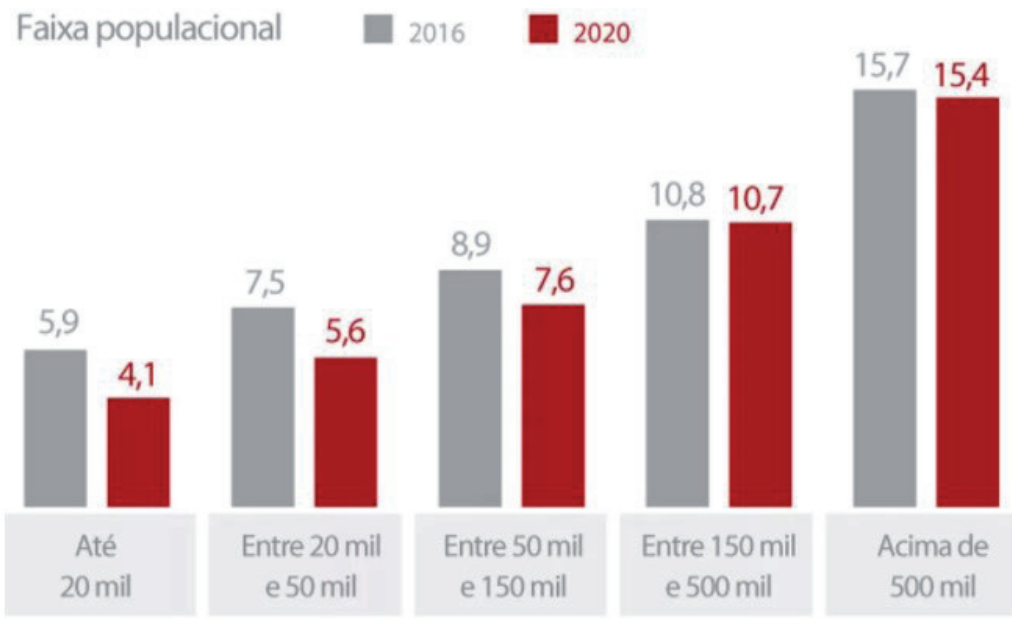

Nota: A base do TSE extraída em 23/11 apresentava 46 casos faltantes da eleição de 2020

Fonte: Vasconcellos (2020).

Igualmente, as disputas nas 26 capitais estaduais ${ }^{8}$ demonstraram a manutenção da dispersão partidária na comparação das eleições de 2016 com as de 2020. Em 11 delas houve queda entre um e cinco no número de

\footnotetext{
${ }^{8}$ Destaca-se que as eleições na capital amapaense não ocorreram de forma concomitante com o restante do país em razão da crise de falta de eletricidade que assolou o Estado em momento próximo às eleições. Assim, enquanto as eleições nos demais municípios brasileiros ocorreram em 15 de novembro (primeiro turno) e 29 de novembro (segundo turno) de 2020, as eleições na cidade de Macapá ocorreram nos dias 6 e 20 de dezembro do mesmo ano.
} 
partidos representados nas respectivas câmaras de vereadores; em outras 11 houve aumento de uma a quatro legendas; e, finalmente, em quatro capitais houve estabilidade no número de partidos com assentos nas câmaras de vereadores. Entre elas, destaca-se o caso de Vitória, em que se elegeram candidatos de 13 partidos diferentes para as 15 vagas em disputa, sendo que apenas o partido Cidadania, elegeu mais de um parlamentar - três no total (VASCONCELLOS, 2020; G1 AP, 2020).

Em outros termos e como se pode perceber na Figura 1, o impacto do fim das coligações se deu essencialmente nas cidades menores em que a competição eleitoral tradicionalmente se mostrava menos intensa. Já nas cidades maiores e marcadas por maior competição, o impacto do fim das coligações no número de partidos com representação parlamentar se mostrou bastante reduzido.

Assim, a ideia de que o fim das coligações partidárias em eleições proporcionais esvaziaria os partidos pequenos ao custo do fortalecimento dos grandes não se mostrou verdadeiro. Em realidade, porém, significou o fortalecimento das lideranças do executivo das menores localidades que tradicionalmente sofriam de uma menor competição política. Ou seja, o fim das coligações significou, ao menos em relação aos dados do processo eleitoral de 2020, um maior fortalecimento dos poderes executivos nos municípios menos sujeitos às dificuldades e às instabilidades da dispersão partidária.

Inclusive, em 14 municípios brasileiros, todos considerados muito pequenos e com menos de 10 mil habitantes, haverá câmaras municipais de partido único (VASCONCELLOS, 2020). Entre eles, exemplificativo é o caso do município de São Pedro dos Crentes, cidade no Sul Maranhense, e com cerca de cinco mil habitantes. Ali, todos os vereadores e o prefeito reeleito são oriundos da mesma agremiação, sendo que em 2016, a Câmara de Vereadores das localidades era composta por parlamentares de quatro partidos diferentes. Isto é, já apresentava baixa dispersão partidária mesmo com a possibilidade de formação de coligações.

Segundo o prefeito reeleito, em declaração ao jornal Folha de S. Paulo, o único projeto polêmico na legislatura municipal de 2016-2020 teria sido a criação da previdência municipal, a qual foi aprovada pelos parlamentares com seis votos favoráveis e três abstenções - isto é, sem grandes dificuldades. O chefe do executivo, por sua vez, ao analisar a composição 
legislativa de 2020-2024 foi categórico: “a expectativa agora é um mandato ainda mais tranquilo” (PITOMBO; GARCIA, 2020).

Registra-se, ainda, em comparação a 2016, o expressivo aumento do número de vereadores eleitos por partidos tais como PP (aumento de $34 \%$ ) indo de 4.743 para 6.346; PSD (aumento de 22\%), indo de 2.650 para 5.694; PL (aumento de 15\%) indo de 3.019 para 3.467; Republicanos (aumento de 60\%) indo de 1.621 para 2.601; e a manutenção do número de vereadores do MDB (com ligeira redução de 3\%) indo de 7.560 para 7.335. Tais partidos podem ser classificados como "partidos-ônibus" na consagrada expressão de FHC ao se referir ao então PMDB, ou "catch-all Party" ("Partido Pega-Tudo") de acordo com Otto Kirchheimer (2012, p. 363-364) ao se referir, por exemplo, ao Democrazia Cristiana italiano.

Em outros termos, as agremiações que mostraram grande força nesse ambiente sem coligações foram partidos sem grande identidade comum, baixa ideologização e pouca conexão com sociedade e que aparentam estar "se concentrando mais completamente no cenário eleitoral, na tentativa de trocar a efetividade do debate mais aprofundado por uma audiência mais ampla e pelo sucesso eleitoral mais imediato" (KIRCHHEIMER, 2012, p. 362).

Não bastasse isso, aponta-se que relatórios de fiscalização da Controladoria Geral da União nos municípios brasileiros, indicam uma correlação positiva entre corrupção e o aumento do volume financeiro oriundo de transferências de recursos da União em favor de municípios. Ademais, aponta-se uma correlação negativa entre corrupção e competitividade entre as forças políticas nos municípios brasileiros (MIRANDA JÚNIOR, 2010) ${ }^{9}$. Logo, quanto mais recursos recebidos da União via transferências e quanto menor a competição eleitoral, maior a tendência ao aumento de níveis de malversação de recursos públicos.

Por sua vez, como bem apontam Bahia dos Santos e Ribeiro Santos (2014), é marcante no federalismo brasileiro que muitos municípios têm

\footnotetext{
${ }^{9}$ Eis a conclusão do estudo de José Costa Miranda Júnior (2010, p. 46-47): "A partir dessa definição, buscou-se um modelo teórico aplicável ao estudo, em que por meio de sua solução foi possível o alcance de duas propriedades: i) a corrupção é correlacionada positivamente com o volume de recursos transferidos aos municípios; e ii) a corrupção possui uma relação negativa com a esperança do ocupante do cargo acerca da competência, ou força do seu oponente. [...] Ou seja, a corrupção é influenciada tanto pelo volume de recursos repassados aos municípios quanto pela esperança acerca da competência do candidato oponente".
} 
baixa capacidade de arrecadação tributária e ampla dependência da transferência de recursos de outros entes federativos. Ainda segundo as autoras, aludida dependência apresenta uma relevância inversamente proporcional ao tamanho do município, sendo que os municípios mais dependentes das transferências de recursos federais são usualmente aqueles com menor população $^{10}$.

Este cenário, portanto, levanta dúvidas sobre o êxito da reforma eleitoral que eliminou a possibilidade de coligações nas eleições proporcionais. Afinal, os resultados parciais até aqui obtidos indicam exatamente um caminho oposto. Ou seja, apontam para permanência da baixa ideologização partidária, bem como reduziram a já comprometida competição política nos pequenos municípios, reforçando a tendência de aumento dos indicadores de corrupção nessas localidades.

\section{Considerações finais}

Na obra Democracy for Realists, Achen e Bartels (2017, p. 76) desafiam, a partir de uma série de casos práticos, uma visão denominada "ingênua" da democracia e que muitas das reformas com o objetivo de se conferir maior legitimação às instituições políticas implicam em resultados absolutamente negativos. Tal qual no Brasil, os Estados Unidos sofrem com uma crise de legitimidade democrática e constante pressão de políticos que se apresentam como "de fora do sistema" supostamente aptos a solucionar os problemas do sistema representativo de forma extralegal. Por sua vez, intentam-se regularmente reformas com a intenção de resgatar o apoio popular às instituições representativas.

Entre essas iniciativas, os autores destacam a imposição de limites ao número de mandatos nos Poderes Legislativos estaduais em algumas localidades estadunidenses. Tais medidas foram exatamente tomadas com o objetivo de reduzir o número de políticos profissionais e tornar aludidos ambientes de decisão política mais abertos aos cidadãos comuns que deles queiram participar. Em realidade, porém, tal medida acabou por significar uma transferência de poder de agentes políticos conhecidos pelos eleitores

\footnotetext{
${ }^{10}$ Isto se dá, pois, segundo os autores, aludida transferência financeira "é muito mais importante para os municípios menores que para os maiores, principalmente pelo fato de que a produção econômica, nesses municípios, provém, principalmente, dos setores agrícolas e de serviços" (BAHIA DOS SANTOS; RIBEIRO SANTOS, 2014, p. 12).
} 
para outros muito mais inacessíveis ao cidadão ordinário - como assessores e burocratas que orbitavam aqueles.

Ainda, em comparação com outros estados em que não havia tal tipo de limitação, percebeu-se que as autoridades legislativas se apresentavam significativamente menos influentes enquanto os governadores e sua equipe passaram a ter ainda mais poder, tendo, por exemplo, muito mais influência nas negociações orçamentárias em face de casas legislativas cujos membros se mostravam menos experientes e hábeis. Igualmente, legislativos com limitação ao número de reeleições produziram políticas públicas menos inovativas.

Portanto, segundo os autores, em lugar de trazer o cidadão comum às assembleias legislativas estaduais, a imposição de limites à reeleição legislativa trouxe ao cenário político pessoas menos experientes, sujeitas à maior influência do Poder Executivo e menos capazes de lidar com os desafios de implementação de políticas públicas. Por consequência, se o objetivo era permitir maior proximidade entre representante e representados e maior confiança dos eleitores nas instituições democráticas, a reforma em questão fracassou (ACHEN; BARTELS, 2017, p. 77).

O mesmo dilema entende-se ocorrer em relação ao fim das coligações nas eleições proporcionais no Brasil. Os dados do primeiro pleito ocorrido sob tal diretriz, indicou seu impacto relevante tão somente nos pequenos e médios municípios, sendo certo que apenas neles ocorreu uma redução significativa da dispersão partidária nas câmaras municipais. Porém, como visto, tais localidades já eram, mesmo antes do fim das coligações, menos marcadas por tal problema.

Portanto, o fim das coligações apenas reduziu a competição política nessas localidades e fortaleceu os executivos dos municípios em regra mais dependentes das transferências de recursos de outros entes federados. Por sua vez, menor competição política e maior dependência de transferência de recursos de outros entes federados, são indicadores de maior potencial de corrupção. Ainda, os dados indicam que os grandes beneficiados com o fim das coligações proporcionais foram os denominadas partidos "catch-all" de baixo perfil ideológico.

Assim, conclui-se que o fim das coligações em eleições proporcionais, em que pese as intenções iniciais, não significou uma aproximação entre cidadão e parlamentar, mas, em realidade, o seu oposto. Logo, é fato 
que a reforma, ao menos em face dos dados iniciais extraídos das eleições de 2020, foi incapaz de alterar a consideração de Weber anteriormente apontada de que os partidos políticos, na modernidade, mostram-se menos unidos pela força gravitacional de certas ideias e mais pelo fisiologismo e pela busca de poder ainda que ao custo da corrupção e desperdícios.

\section{Referências}

ACHEN, Christopher; BARTELS, Larry. Democracy for realists: why elections do not produce responsive government. Princeton: Princeton University Press, 2017.

BAHIA DOS SANTOS, Karla Gabriele; RIBEIRO SANTOS, Carlos Eduardo. Dependência Municipal das Transferências do Fundo de Participação dos Municípios. In: IV Semana do Economista, IV, 2014. Anais [...]. Ilhéus: Universidade Estadual de Santa Cruz, 2014. p. 1-21. Disponível em: http:/ / www.uesc.br/eventos/ivsemeconomista/anais/gt1-5. Acesso em: jun. 2021.

\section{CÂMARA DOS DEPUTADOS. Proposta de Emenda à Constituição} no 282, de 2016. Comissão de Constituição e Justiça e de Cidadania. Brasília, 2017. Disponível em: https:/ /www.camara.leg.br/proposicoesWeb/ prop_mostrarintegra? codteor $=1541803 \&$ filename $=$ PRL $+1+C C J C+\%$ 3D\%3E+PEC+282/2016. Acesso em: 2 dez. 2020.

CASTELLS, Manuel. Ruptura: a crise da Democracia Liberal. Tradução de Joana Angélica d'Avila de Melo. Rio de Janeiro: Zahar, 2018.

CURCINO, Naiôn. Candidata mais votada não consegue vaga na Câmara de Santa Maria. Gazeta Zero Hora, Porto Alegre, 17 nov. 2020. Disponível em: https://gauchazh.clicrbs.com.br/politica/eleicoes/noticia/2020/11/ candidata-mais-votada-nao-consegue-vaga-na-camara-de-santa-maria-ckhm90oiw0001016gweqe98gx.html. Acesso em: 4 dez. 2020.

DAHL, Robert. Sobre a democracia. Tradução de Beatriz Sidou. Brasília: UNB, 2001.

G1 AP. Veja os 23 vereadores eleitos em 2020 para Macapá. G1, Amapá, 6 dez. 2020. Disponível em: https://g1.globo.com/ap/amapa/eleicoes/2020/ noticia/2020/12/06/veja-os-23-vereadores-eleitos-em-2020-para-macapa. ghtml. Acesso em: 21 jan. 2021. 
G1 PR. Candidata mais votada não é eleita vereadora, em Toledo. G1, São Paulo, 17 nov. 2020. Disponível em: https://g1.globo.com/pr/oeste-sudoeste/noticia/2020/11/17/candidata-mais-votada-nao-e-eleita-vereadora-em-toledo.ghtml. Acesso em: 4 dez. 2020.

GIELOW, Igor. Avaliação do Congresso piora em meio a trégua com Bolsonaro, aponta Datafolha. Folha de S. Paulo, São Paulo, 16 ago. 2020. Disponível em: https://www1.folha.uol.com.br/poder/2020/08/avaliacao-do-congresso-piora-em-meio-a-tregua-com-bolsonaro-aponta-datafolha.shtml. Acesso em: 2 dez. 2020.

KIRCHHEIMER, Otto. A transformação dos sistemas partidários da Europa Ocidental. Tradução Paulo Peres. In: Revista Brasileira de Ciência Política, n. 7, jan./abr. 2012.

LEBRUN, Gerard. O que é Poder? Tradução de Renato Janine Ribeiro. São Paulo: Abril Cultural, 1984.

PITOMBO, João Pedro; GARCIA, Guilherme. 1 em cada 10 Câmaras terá só dois partidos, resultado do fim das coligações eleitorais. Folha de S. Paulo, São Paulo, 1 dez. 2020. Disponível em: https://www1.folha.uol.com.br/ poder/2020/12/uma-em-cada-dez-camaras-municipais-tera-apenas-dois-partidos.shtml. Acesso em: 5 dez. 2020.

MAZOWER, Mark. Continente sombrio: a Europa do século XX. Tradução de Hildegard Feist. São Paulo: Companhia das Letras, 2001.

MIRANDA JÚNIOR, José Costa. A corrupção nos municípios brasileiros: uma análise a partir dos relatórios de fiscalização produzidos pela Controladoria Geral da União. Dissertação (Mestrado em Economia do Setor Público) - Universidade de Brasília, Brasília, 2010.

NICOLAU, Jairo. Sistemas eleitorais. 6. ed. São Paulo: Ed. FGV, 2012.

SANSON, Alexandre; TORRES, Vivian de Almeida Gregori. As coligações partidárias na reforma política de 2015: evolução histórico-normativa e propostas de mudança. In: CAGGIANO, Monica Herman (org.). Reforma política: um mito inacabado. Barueri: Manole, 2017.

TAVARES, André Ramos. A jurisprudência sobre partidos políticos no Supremo Tribunal Federal: entre eleições, poder econômico e democracia. In: NORONHA, João Otávio de et. al. (org.). Sistema político e direito eleitoral brasileiros: estudos em homenagem ao Ministro Dias Toffoli. São Paulo: Atlas, 2016. 


\section{TRIBUNAL SUPERIOR ELEITORAL. Partidos políticos registrados no}

TSE. Brasília, 2020. Disponível em: https://www.tse.jus.br/partidos/partidos-politicos/registrados-no-tse. Acesso em: 2 dez. 2020.

VASCONCELLOS, Fábio. Em 14 cidades, um único partido vai controlar a Câmara Municipal. G1, São Paulo, 22 nov. 2020. Disponível em: https://g1.globo.com/politica/eleicoes/2020/eleicao-em-numeros/noticia/2020/11/22/em-14-cidades-um-unico-partido-vai-controlar-a-camara-municipal.ghtml. Acesso em: 4 dez. 2020.

VASCONCELLOS, Fábio. Fim das coligações reduz número de partidos nas Câmaras em 73\% das cidades. G1, São Paulo, 25 nov. 2020. Disponível em: https://g1.globo.com/politica/eleicoes/2020/eleicao-em-numeros/noticia/2020/11/25/ fim-das-coligacoes-reduz-numero-de-partidos-nas-camaras-em-73percent-das-cidades.ghtml. Acesso em: 4 dez. 2020.

WEBER, Max. Política como vocação. Tradução de Marcelo Rondinelli. In: BOTELHO, André (org.). Sociologia essencial. São Paulo: Penguin Classics/Cia das Letras, 2013.

Bruno de Almeida Passadore - Doutorando em Teoria do Estado pela Universidade de São Paulo (USP). Mestre em Direito Processual pela mesma instituição. Defensor público estadual em Curitiba. Diretor da Escola da Defensoria Pública do Estado do Paraná. e-mail: bruno.passadore@usp.br ORCID: 0000-0002-7513-1377.

Camila Rodrigues Forigo - Doutoranda em Direito Penal pela Universidade de São Paulo (USP). Mestre em Direito Econômico e Desenvolvimento pela Pontifícia Universidade Católica do Paraná (PUCPR). Especialista em Direito Penal e Criminologia pelo Instituto de Criminologia e Política Criminal (ICPC). Conselheira do Instituto Brasileiro de Direito Penal Econômico (IBDPE). Secretária da Comissão da Advocacia Criminal da OAB-PR (Triênio 2019-2021). Advogada. e-mail: camila.forigo@usp.br ORCID: 0000-0002-5046-0713. 